\title{
1 Yeast single cell protein production from a 2 biogas co-digestion substrate
}

3

4 Jonas A. Ohlsson, Matilda Olstorpe, Volkmar Passoth, and Su-lin L. Leong

5

6 Department of Molecular Sciences, Swedish University of Agricultural Sciences, Uppsala,

7 Sweden

8

9 Corresponding author: Su-lin L. Leong <su-lin.leong@slu.se>

10 Address: Department of Molecular Sciences, Swedish University of Agricultural

11 Sciences, Box 7015, SE-750 07 Uppsala, Sweden

12 


\section{Abstract}

14 Biogas plants serve as hubs for the collection and utilization of highly nutritious waste streams from households and agriculture. However, their outputs (biogas and digestate) are of relatively low economic value. Here, we explore the co-production of yeast single cell protein, a potentially valuable feed ingredient for aquaculture and other animal producing industries, with biogas on substrate collected at a codigestion biogas plant, using three yeast species well suited for this purpose (Wickerhamomyces anomalus, Pichia kudriavzevii, and Blastobotrys adeninivorans). All yeasts grew rapidly on the substrate, yielding $7.0-14.8 \mathrm{~g} \mathrm{l}^{-1}$ biomass after $12-15$ h. The biomass crude protein contents were $22.6-32.7 \%$, with relatively favorable amino acid compositions mostly deficient in methionine and cysteine. Downstream biomethanation potential was significantly different between yeast species, with the highest product yielding species (Blastobotrys adeninivorans) also yielding the highest biomethanation potential.

Highlights

- All yeasts grew well on the biogas substrate, with high growth rates.

- Produced biomass was of high nutritional value for use in fish feed formulations.

- Downstream effects on methane potential were strain-dependent.

- Yeast biomass may be a viable biogas co-product. 
Amino acid(s)

$38 \quad A D$

Anaerobic digestion

39 BMP

Biomethanation potential

40

CL Crude lipid

$41 \mathrm{CP}$

Crude protein

42 EAA

Essential amino acid(s)

43 FM

Fish meal

44 NS

Native substrate

45

OFMSW

Organic fraction of municipal solid waste

46 SCP

Single cell protein

$47 \quad$ TS

Total solids

48

VS

Volatile solids

\section{Introduction}

51 The organic fraction of municipal solid waste (OFMSW) is a major waste stream

52 which contains ample amounts of energy and nutrients available for microbial

53 conversion into higher value products. In the EU, policy changes such as the EC

54 Council Directive 1999/31/EC of 26 April 1999, by which member states are obligated

55 to reduce the amount of OFMSW being deposited on landfills, have increased

demands for alternative waste processing facilities such as anaerobic digestion (AD)

57 plants. AD plants convert waste streams into biogas and a post-digestion residue mainly being used as fertilizer. OFMSW is typically co-digested with agricultural residues such as manure, a practice which improves biogas yields as well as reduces emissions of methane and odours from farms (Holm-Nielsen et al., 2009). 
61 Moreover, biogas production by AD is in line with other policies aimed at improving energy security and usage of renewable energy. In concert with the implementation of several such policies, the installed capacity of AD in Europe has seen a steep

64 increase since the turn of the century (Scarlat et al., 2018), and future demand may rise further if new uses such as biomethane-based power grid balancing, which offsets energy fluctuations due to large parts of solar and wind in the energy mix, see widespread deployment (Peters et al., 2018).

The widespread adoption of OFMSW as a substrate for AD has at least two main implications that warrant considering AD plants as well suited for expanding their product portfolios: first, the year-round and constant availability of readily biodegradable substrate of relatively stable composition (Hartmann and Ahring, 2006), and, second, the presence of well-developed logistic networks for the collection and transportation of substrate. Furthermore, AD substrate is typically pretreated in several ways including removal of certain contaminants, size reduction, and hygienization; unit operations which render the material more amenable to microbial conversion (Carlsson et al., 2012).

Although biogas and digestate represent outputs that provide value, both are lowvalue commodities. There are several recently proposed methods for improving the

81 financial proposition of biogas plants by altering the output streams towards more

82 valuable products (see e.g., Kleerebezem et al. (2015), Monlau et al. (2015)). One 83 possible value-added co-product of a biorefinery is yeast biomass intended as animal 84 feed. A particularly promising consumer of microbial protein feed sources is the 
aquaculture industry. While outputs from marine fisheries are probably declining (FAO, 2018), aquaculture today supplies $53 \%$ of direct global fish consumption (FAO, 2018), and as the fastest growing food producing sector over the last 40 years

88 it will play a crucial role in feeding the growing world population (Béné et al., 2015). A

89 major ingredient in aquaculture feed, especially for carnivorous fish species is fish meal (FM), which is derived from wild-caught fish. With an ever-widening gap between production of wild and farmed fish, availability of FM is becoming a major limiting factor for further expansion of fish farming (Tacon and Metian, 2009). Although feed ingredients of vegetable origin are used for replacing FM in feed formulations, higher inclusion levels may negatively affect fish growth due to antinutritional factors present in many vegetable feed sources (Francis et al., 2001). Moreover, vegetable feed ingredients, as well as FM, may directly be at odds with human food interests (Tacon and Metian, 2009).

98

Microbial biomass used for feed is commonly referred to as single cell protein (SCP), and its use in animal feed is well established for both fish and other animals (Goldberg, 1985). Targeting fish feed is especially beneficial as fish are able to metabolize the nucleic acids that are present in large amounts in yeast biomass,

103 whereas high contents of nucleic acids in the diet can cause adverse health effects in some other animals (Rumsey et al., 1992). Yeast biomass has been successfully used in fish feed formulations, both at low inclusion levels for its appetite stimulating, 106 nutritional, or immunostimulatory properties, and at higher levels as FM replacement 107 where it is generally well tolerated up to a certain level (reviewed in Delgado and 108 Reyes (2018)). SCP production is desirable from a food security perspective, and the 
demand for fish feed ingredients, including FM replacements, are likely to increase due to the concomitant expansion of aquaculture and decrease in marine fish stocks.

112 Organisms suitable for SCP production on OFMSW should, first and foremost, be 113 able to utilize a large array of substrate molecules. Other desirable characteristics

114 include phytase production, as this may improve nutritional quality of the feed if 115 ingredients of vegetable origin are included in the formulation (Cao et al., 2007), as 116 well as the ability to outcompete other organisms due to the non-sterile nature of the 117 substrate. In this study, we evaluated three yeast species with suitable properties for 118 SCP production on typical co-digestion AD substrate: Wickerhamomyces anomalus,

119 a metabolically versatile species which has shown robustness to difficult growth 120 conditions, has been evaluated in fish feeding trials and which is known for its

121 biocontrol properties as well as being a phytase producer (Huyben et al., 2017;

122 Olstorpe et al., 2009; Passoth et al., 2006; Passoth et al., 2010; Schnürer and 123 Jonsson, 2010); Pichia kudriavzevii, another robust yeast known for its ability to grow 124 in the presence of inhibitory substances, and which has been reported to produce 125 extracellular phytase (Hellström et al., 2015; Olstorpe et al., 2009; Radecka et al., 2015), and Blastobotrys adeninivorans, known for its ability to utilize a large variety of

127 carbon and nitrogen sources, as well as for its high production of intra- and extracellular phytase (Middelhoven et al., 1991; Olstorpe et al., 2009; Sano et al., 129 1999).

131 The aim of this study was to investigate whether production of yeast biomass in 132 combination with AD could be a feasible option for further diversification of production 
133

134

outputs from biogas plants. We have evaluated growth performance of yeasts on biogas substrate obtained from a Swedish co-digestion biogas plant, characteristics of the resulting biomass, and the effects of yeast cultivation on downstream chemical composition and biomethanation potential (BMP).

\section{Materials and methods}

\subsection{Inoculum preparation and culture media}

Yeast strains (W. anomalus CBS 100487, P. kudriavzevii CBS 2062, and B. adeninivorans CBS 7377 ), stored in $50 \%$ glycerol stocks at $-80^{\circ} \mathrm{C}$, were inoculated onto YPD agar (10 $\mathrm{g} \mathrm{l}^{-1}$ yeast extract (BD, Le Pont-de-Claix, France), $20 \mathrm{~g} \mathrm{l}^{-1}$ bacterial peptone (BD, Le Pont-de-Claix, France), $20 \mathrm{~g} \mathrm{l}^{-1} \mathrm{D}$-glucose (Merck, Darmstadt, Germany), and $20 \mathrm{~g} \mathrm{l}^{-1}$ agar (BD, Le Pont-de-Claix, France)). Inoculum cultures were prepared using the same medium, without agar, in 125-ml baffled Erlenmeyer flasks (Thomson Ultra-Yield, Thomson Instrument Co., Carlsbad, CA, USA), and cultivated on a rotary shaker for $24 \mathrm{~h}$. Cells were harvested at $3000 \times g$ for 5 min and washed with saline $\left(\mathrm{NaCl}, 9 \mathrm{~g} \mathrm{l}^{-1}\right)$ using the same settings.

\subsection{Substrate preparation}

The biogas substrate was obtained directly from the inlet to the digester at a biogas plant in Sweden, and consisted mainly of source-separated household waste, organic waste from municipal kitchens, and liquid agricultural waste (swine and cattle manure). Metals and plastics had been mechanically removed at the biogas plant, 
155

156

157

158

159

160

161

162

163

164

165

166

167

168

169

170

171

172

173

174

175

176

177

178

and the substrate had been hygienized at $70^{\circ} \mathrm{C}$ for $>1 \mathrm{~h}$. This substrate will be referred to as native substrate (NS).

To be able to separate yeast biomass after culturing, and to reduce the risk of contamination as substrate was collected through a non-sterile sampling port at the biogas plant, the substrate was sterile-filtered. This was accomplished using an Asahi Rexeed-25A hemodialyzer (Asahi Kasei Medical Co., Ltd., Tokyo, Japan) connected to a peristaltic pump, with the filter replaced when the counterpressure reached 0.6 bar. The filtered substrate was then sterile-filtered through a $0.2 \mu \mathrm{m}$ sodium acetate filter (Nalgene Rapid-Flow, Thermo Fisher Scientific, Waltham, MA, USA) using a Büchner funnel.

\subsection{Bioreactor operation}

500-ml Infors HT Multifors CSTR bioreactors (Infors AG, Bottmingen, Switzerland) were used for the cultivations. For each reactor, $400 \mathrm{ml}$ of the sterile-filtered substrate was inoculated at an initial $\mathrm{OD}_{600}$ of 1.0 . Reactor parameters were $\mathrm{pH}=$ $7.00 \pm 0.10$, stirrer $=500 \mathrm{rpm}$, and $\mathrm{pO}_{2}=0.2 . \mathrm{pO}_{2}$ was maintained using stirrer speed, with a minimum of $200 \mathrm{rpm}$ and a maximum of $1200 \mathrm{rpm}$. $\mathrm{pH}$ was automatically adjusted on-line using $5 \mathrm{M} \mathrm{NaOH}$ and $3 \mathrm{M} \mathrm{H}_{3} \mathrm{PO}_{4}$.

Fermenter temperature was set to $30^{\circ} \mathrm{C}$ for all cultivations, except for the evaluation of $B$. adeninivorans CBS 7377 growth performance. This strain exhibited better growth at $37^{\circ} \mathrm{C}$ during initial growth assessment (results not shown), so growth was evaluated at this temperature. 


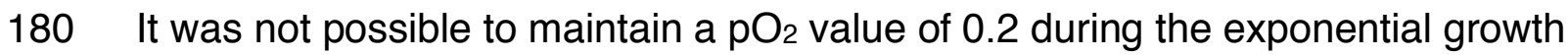

181 phase, due to the high oxygen consumption of the yeast. Cultivations were

182 terminated after the log phase was completed, as indicated by $\mathrm{pO}_{2}$ readings.

183

184 To monitor the fermentations, viable cell counts were performed. Due to the complexity and optical activity of the medium, plating was chosen instead of OD measurements. Relevant dilutions, made with $1 \mathrm{~g} \mathrm{I}^{-1}$ peptone water, were plated onto YMC agar (3 $\mathrm{g} \mathrm{l}^{-1}$ yeast extract, $3 \mathrm{~g} \mathrm{I}^{-1}$ malt extract (BD, Le Pont-de-Claix, France), 5 units (CFU) were counted when colonies were clearly visible.

After fermentation, bioreactor contents were centrifuged at $3000 \times g$ for $10 \mathrm{~min}$. The pellets, containing yeast biomass, were washed with deionized water using the same centrifuge settings, and stored at $-20^{\circ} \mathrm{C}$.

\subsection{Biomethanation potential assay}

197 To assess downstream effects of yeast cultivation on biogas performance, spent medium was collected from cultivations of each yeast. Cultivations were performed largely as described in Section 2.3. In order to minimize confounding factors, all

200 cultivations were terminated at the same time (i.e., the time was determined by the 201 growth performance of the slowest growing yeast), and were run at the same temperature $\left(30^{\circ} \mathrm{C}\right)$. This was needed to ensure that evaporative losses of volatile 
energy carriers, such as short-chain carboxylic acids, were similar between the treatments. At the end of cultivation, yeast biomass was collected as described in

205 Section 2.3, and the supernatants, referred to as spent media, collected.

The BMP assay was conducted largely according to Angelidaki et al. (2009). In brief,

total solids (TS) and volatile solids (VS) of NS and spent medium (supernatants, post yeast-treatment) were determined by drying the substrates at $105^{\circ} \mathrm{C}$ and incinerating at $550^{\circ} \mathrm{C}$ in aluminum containers, noting the weights after each step. TS was

211 calculated as the quotient of dry matter divided by initial weight. VS was determined 212 as the difference between TS and ash content.

214 The assay was performed using untreated NS and fresh inoculum (collected from the same biogas plant and degassed for 3 days at $37^{\circ} \mathrm{C}$ ), contributing approximately 1.2

$216 \mathrm{~g}$ VS and $3.6 \mathrm{~g} \mathrm{VS}$, respectively. The substrate control treatment contained only NS 217 and inoculum. Spent medium was added in the remaining treatments, so that the 218 mixtures contained, by weight, NS:spent medium in ratios of 10:1, 10:3, 2:1, and 1:1, 219 which corresponded to $9-50 \%$ spent medium in the final AD slurry. Due to the low 220 VS content of the spent medium, increases in VS due to supernatant additions were

221 modest, at most $20 \%$, and it was assumed that this slight change in

222 inoculum:substrate ratio would not affect inoculum performance. Inoculum and

223 cellulose process controls were included. The inoculum control, used for

224 determination of background methane production, consisted of inoculum contributing

$2253.6 \mathrm{~g} \mathrm{VS}$. The cellulose control, needed for evaluating the function of the inoculum, 226 contained $3 \mathrm{~g}$ cellulose (medium fibers; Sigma-Aldrich, Steinheim, Germany) and 400 
$227 \mathrm{ml}$ of inoculum. Tap water was added to each bottle to a final volume of $400 \mathrm{ml}$, and each treatment was evaluated in triplicate.

229

To measure methane production, AMPTS II Automatic Methane Potential Test

231 Systems (BioProcess Control AB, Lund, Sweden) were used, detailed in Badshah et al. (2012). Briefly, gas volume measuring was performed using a piston system, and gas was upgraded by flushing it through $7 \mathrm{M} \mathrm{NaOH}$. Samples were agitated using

234 stirrers attached directly to the bottles. The assay was performed at $37^{\circ} \mathrm{C}$, as this 235 was the temperature used in the commercial digester from which the inoculum was 236 derived. Bottles were flushed with $\mathrm{N}_{2}$ gas prior to initiating the experiment. Specific methane potential was obtained by dividing the volume of methane produced by the actual amount of VS in each sample. When less than one reading per day was generated from all samples (i.e. the piston did not register any methane gas emissions for $24 \mathrm{~h}$ ), the assay was determined to be complete. Each AMPTS II

241 system contained an identical set of samples so that the response of each system 242 could be included in the statistical model (Section 2.6).

\subsection{Chemical analyses}

245 Chemical analyses were purchased from external labs. Crude protein (CP) content

246 was determined using the total nitrogen Kjeldahl method, and CP was calculated as

$247 \mathrm{~N} \times 6.25$ (Nordic Committee on Food Analysis, 2003). Crude lipid (CL) content was

248 determined according to (The Commission of the European Communities, 1998).

249 Gross nutritional analyses were performed at the VHC lab (SLU, Uppsala, Sweden).

250 Amino acid (AA) analyses were performed according to the ISO 13903:2005 method 
251 (Eurofins Food \& Agro, Jönköping, Sweden). Micronutrient compositions of spent

252 medium (supernatants, yeast biomass removed), sterile-filtered medium, and NS

253 were analyzed using ICP-MS (Agrilab AB, Uppsala, Sweden). Dry matter was

254 determined by drying the samples at $105^{\circ} \mathrm{C}$ until constant weight was achieved.

255

256 When possible, analyses were performed in replicates. For the BMP assay, each

257 yeast treatment was carried out in a single bioreactor to ensure equal freshness and

258 composition of the spent medium, and the replicates represent aliquots of the

259 supernatants. For pellet (yeast biomass) characterization, four replicate

260 fermentations were carried out. Spent medium compositional analyses were

261 performed using material pooled from all bioreactors.

262

263

\subsection{Calculations and statistical analyses}

264 The maximum growth rate $\left(\mu_{\max }\right)$ was estimated by taking the greatest slope of the

265 growth curve

266

$$
y(t)=\frac{\ln N(t)}{\ln N(0)}
$$

267 where $N(t)$ is the number of CFU at timepoint $t$. Final biomass productivity was

268 calculated by dividing final biomass concentration by the total cultivation time.

269 Maximum growth rates and final productivities were calculated independently for

270 each fermenter.

272 AA scores for the yeast biomass, reflecting the requirements of essential amino acids

273 (EAA), were calculated based on finfish requirements as reported in Tacon et al.

274 (2009). 
276 To evaluate the downstream effects of spent substrate addition on biomethanation

277 potential, a linear model was fitted according to the formula

$$
y_{i j k}=a_{i}+b_{j}+c_{k}+(b c)_{j k}+\varepsilon_{i j k}
$$

279 where $y_{i j k}$ is the biomethanation potential of the sample, $a$ is the effect of each

280 AMPTS II system, $b$ is the effect of strain, $c$ is the effect of spent medium at level $k$ in

281 the reactor, $(b c)$ is the interaction term for dose $\times$ strain, and $\varepsilon$ is the residual. The

282 model was fitted using the built-in function $\mathrm{Im}()$ in $\mathrm{R}$ version 3.6.0 (R Core Team,

283 2019). All graphs were generated using ggplot2 version 3.1.1 (Wickham, 2009).

284

\section{Results}

\subsection{Yeast cultivation and biomass characterization}

287 Native biogas substrate (NS) was sterile-filtered and the three yeast strains were

288 cultured on this substrate in the fermenters. Fermentations were terminated after 12-

28915 hours, yielding approximately $2 \log _{10}$ increases for strains $P$. kudriavzevii CBS

2062 and $B$. adeninivorans CBS 7377, and approximately a $1.5 \log _{10}$ increase for $W$.

291 anomalus CBS 100487 (Figure 1), with high maximum growth rates $\left(\mu_{\max }\right)$ of $0.48-$

$0.76 \mathrm{~h}^{-1}$ (Table 1).

293

294 Final biomass concentrations ranged from $7.0 \mathrm{~g} \mathrm{l}^{-1}(22.6 \% \mathrm{CP})$ for $W$. anomalus to $29514.8 \mathrm{~g} \mathrm{l}^{-1}(30.5 \% \mathrm{CP})$ for $B$. adeninivorans. Final biomass productivities ranged from $2960.53 \mathrm{~g} \mathrm{l}^{-1} \mathrm{~h}^{-1}$ for $P$. kudriavzevii to $0.99 \mathrm{~g} \mathrm{l}^{-1} \mathrm{~h}^{-1}$ for $B$. adeninivorans (see Table 1 for 297 the kinetic parameters and gross nutritional characterization of the yeast biomass). 
299 Protein content according to the AA analysis was largely in agreement with CP

300 values, indicating that most nitrogen present in the biomass originated from protein

301 (Table 2). Yeast biomass AA composition was similar for all three species, with $W$.

302 anomalus notably having a somewhat lower content of methionine and cysteine,

303 sulfur-containing EAA, compared to the other two yeasts. In general, yeast biomass

304 was deficient in arginine and in the sulfur-containing AA relative to the requirements

305 of finfish, whereas other AA where either in excess or at similar levels (Table 2). EAA

306 made up approximately half of the AA present in yeast biomass.

307 

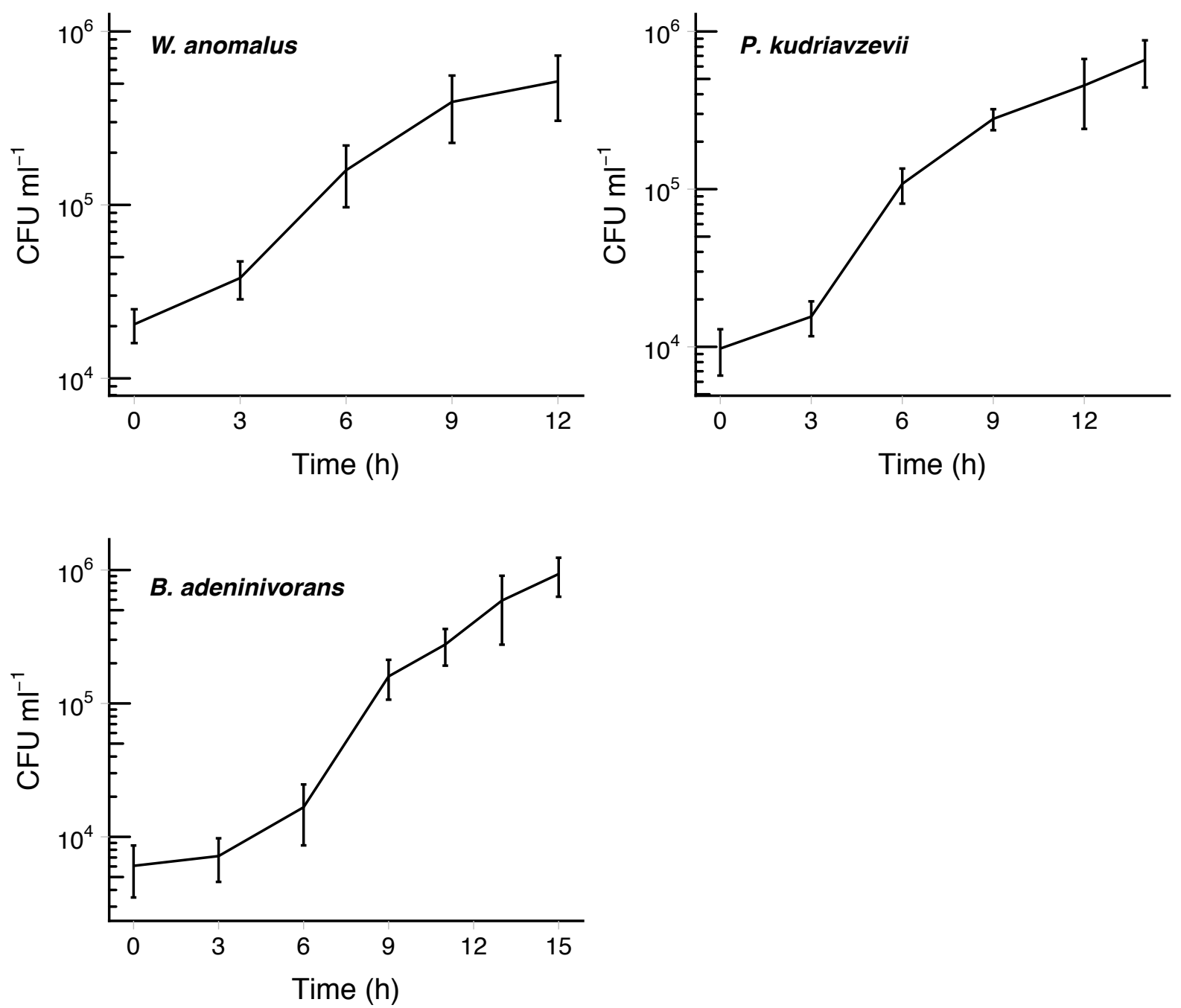

309 Figure 1. Growth curves for the yeast cultivation trials. Bars represent standard

310 deviation. W. anomalus and P. kudriavzevii were grown at $30^{\circ} \mathrm{C}$, and $B$.

311 adeninivorans at $37^{\circ} \mathrm{C}$. 
312 Table 1. Nutritional characterization of washed yeast biomass, on a dry matter basis.

313 Missing standard deviations indicate that measurements were performed on pooled

314 replicates

\begin{tabular}{|c|c|c|c|c|c|c|}
\hline \multirow[b]{2}{*}{ Parameter } & \multicolumn{2}{|c|}{ W. anomalus } & \multicolumn{2}{|c|}{ P. kudriavzevii } & \multicolumn{2}{|c|}{ B. adeninivorans } \\
\hline & Value & SD & Value & SD & Value & SD \\
\hline$N$ & $3^{a}$ & & 4 & & $3^{a}$ & \\
\hline Biomass concentration $(\mathrm{g} / \mathrm{l})$ & 7.03 & 0.08 & 7.36 & 0.34 & 14.83 & 1.02 \\
\hline$\mu_{\max }\left(h^{-1}\right)$ & 0.48 & 0.10 & 0.64 & 0.06 & 0.76 & 0.06 \\
\hline $\begin{array}{l}\text { Final biomass productivity } \\
(g / l \cdot h)\end{array}$ & 0.59 & 0.01 & 0.53 & 0.02 & 0.99 & 0.07 \\
\hline Crude energy (MJ/kg) & 11.05 & - & 11.91 & - & 13.05 & - \\
\hline Crude protein (\%) & 22.59 & 0.35 & 32.71 & 0.54 & 30.46 & 1.22 \\
\hline Ash (\%) & 45.77 & 0.42 & 42.88 & 0.85 & 37.58 & 2.92 \\
\hline Crude lipid (\%) & 2.68 & - & 1.76 & - & 1.56 & - \\
\hline $\mathrm{Ca}(\mathrm{g} / \mathrm{kg})$ & 145.6 & - & 123.6 & - & 115.0 & 7.23 \\
\hline$K(g / k g)$ & 7.4 & - & 11.1 & - & 16.4 & 2.07 \\
\hline$P(g / k g)$ & 6.6 & - & 11.1 & - & 6.9 & 2.57 \\
\hline$M g(g / k g)$ & 4.7 & - & 3.7 & - & 11.2 & 0.80 \\
\hline $\mathrm{Na}(\mathrm{g} / \mathrm{kg})$ & 83.3 & - & 85.3 & - & 76.7 & 0.93 \\
\hline$S(g / k g)$ & 3.0 & - & 3.6 & - & 4.3 & 0.40 \\
\hline
\end{tabular}

a One sample was excluded due to equipment malfunction. 
bioRxiv preprint doi: https://doi.org/10.1101/766345; this version posted September 12, 2019. The copyright holder for this preprint (which

was not certified by peer review) is the author/funder, who has granted bioRxiv a license to display the preprint in perpetuity. It is made available under aCC-BY 4.0 International license.

316 Table 2. Amino acid composition of dried yeast biomass. Tryptophan contents were not

317 analyzed

\begin{tabular}{|c|c|c|c|c|c|c|c|c|c|}
\hline & \multicolumn{3}{|c|}{ W. anomalus } & \multicolumn{3}{|c|}{ P. kudriavzevii } & \multicolumn{3}{|c|}{ B. adeninivorans } \\
\hline & $\begin{array}{l}\text { Content } \\
\text { (g/100 g) }\end{array}$ & $\begin{array}{c}\text { Content } \\
\text { (weight } \\
\% \text { ) }\end{array}$ & $\begin{array}{c}\text { AA } \\
\text { score }^{a}\end{array}$ & $\begin{array}{l}\text { Content } \\
\text { (g/100 g) }\end{array}$ & $\begin{array}{c}\text { Content } \\
\text { (weight } \\
\% \text { ) }\end{array}$ & $\begin{array}{c}\text { AA } \\
\text { score }\end{array}$ & $\begin{array}{l}\text { Content } \\
\text { (g/100 g) }\end{array}$ & $\begin{array}{c}\text { Content } \\
\text { (weight } \\
\% \text { ) }\end{array}$ & $\begin{array}{c}\text { AA } \\
\text { score }\end{array}$ \\
\hline Alanine & 1.55 & 8.8 & & 1.71 & 6.4 & & 1.93 & 7.7 & \\
\hline Arginine & 0.87 & 5.0 & 85 & 1.35 & 5.0 & 82 & 1.36 & 5.4 & 95 \\
\hline Aspartic acid & 1.88 & 10.7 & & 3.32 & 12.4 & & 2.42 & 9.7 & \\
\hline Cysteine & 0.157 & 0.9 & 67 & 0.274 & 1.0 & 70 & 0.275 & 1.1 & 81 \\
\hline Glutamic acid & 2.63 & 15.0 & & 3.73 & 13.9 & & 4.08 & 16.4 & \\
\hline Glycine & 0.84 & 4.8 & & 1.30 & 4.9 & & 1.28 & 5.1 & \\
\hline Histidine & 0.351 & 2.0 & 83 & 0.594 & 2.2 & 88 & 0.572 & 2.3 & 96 \\
\hline Hydroxyproline & $<0.05$ & - & & $<0.05$ & - & & $<0.05$ & - & \\
\hline Isoleucine & 0.87 & 4.9 & 131 & 1.42 & 5.3 & 133 & 1.1 & 4.4 & 120 \\
\hline Leucine & 1.36 & 7.7 & 114 & 2.11 & 7.9 & 110 & 1.84 & 7.4 & 110 \\
\hline Lysine & 1.41 & 8.0 & 95 & 2.22 & 8.3 & 93 & 1.74 & 7.0 & 84 \\
\hline Methionine & 0.242 & 1.4 & 50 & 0.529 & 2.0 & 69 & 0.417 & 1.7 & 63 \\
\hline Ornithine & $<0.01$ & - & & $<0.01$ & - & & $<0.01$ & - & \\
\hline Phenylalanine & 0.84 & 4.8 & 100 & 1.31 & 4.9 & 97 & 1.09 & 4.4 & 94 \\
\hline Proline & 0.75 & 4.3 & & 1.06 & 3.9 & & 1.44 & 5.8 & \\
\hline Serine & 1.06 & 6.1 & & 1.49 & 5.6 & & 1.44 & 5.8 & \\
\hline Threonine & 0.99 & 5.6 & 106 & 1.66 & 6.2 & 110 & 1.39 & 5.6 & 107 \\
\hline Tyrosine & 0.76 & 4.4 & 134 & 1.15 & 4.3 & 125 & 1.00 & 4.0 & 125 \\
\hline Valine & 0.96 & 5.5 & 115 & 1.58 & 5.9 & 117 & 1.55 & 6.2 & 132 \\
\hline Total & 17.52 & 100.0 & & 26.81 & 100.0 & & 24.92 & 100.0 & \\
\hline Total EAA & 8.81 & 50.3 & & 14.20 & 53.0 & & 12.33 & 43.0 & \\
\hline
\end{tabular}

318

319 a The AA score reflects dietary requirements of essential amino acids in finfish, with

320 values below 100 indicating deficiency. Essential amino acid requirements of finfish

321 are according to Tacon et al. (2009). 


\subsection{Characterization of spent medium}

323 Filtration of the substrate removed a considerable amount of nutrients, presumably

324 contained in particulate matter. Compared to NS, filtered substrate contained 5-fold

325 less VS, 2.1-fold less total N, and 4.5-fold less total C (Table 3). Compared to the

326 filtered supernatant, spent medium contained less TS, VS, C and N, and generally

327 reduced levels of micronutrients. The exceptions were $\mathrm{Na}$, which increased in all

328 treatments, and $\mathrm{P}$, which increased in two out of three treatments. This is most likely

329 due to the use of $\mathrm{NaOH}$ and $\mathrm{H}_{3} \mathrm{PO}_{4}$ for $\mathrm{pH}$ control. Treatment with $P$. kudriavzevii

330 yielded the lowest reduction in TS and VS.

331 
332 Table 3. Chemical composition of substrate before (native) and after filtration, and

333 after yeast fermentation

Post-fermentation supernatants

\begin{tabular}{|c|c|c|c|c|c|}
\hline & \multirow[b]{2}{*}{ Native } & \multirow[b]{2}{*}{ Filtered } & \\
\hline & & & W. anomalus & P. kudriavzevii & B. adeninivorans \\
\hline TS (\%) & 7.8 & 2.1 & 1.5 & 1.6 & 1.2 \\
\hline VS (\% of TS) & 86.3 & 67.2 & 49.8 & 63.9 & 47.9 \\
\hline Total N $\left(g \mathrm{~kg}^{-1}\right)$ & 2.7 & 1.3 & 0.6 & 0.5 & 0.3 \\
\hline Organic $N\left(g \mathrm{~kg}^{-1}\right)$ & 2.2 & 0.8 & 0.2 & 0.4 & 0.2 \\
\hline $\mathrm{NH}_{4}^{+-} \mathrm{N}\left(\mathrm{g} \mathrm{kg}^{-1}\right)$ & 0.5 & 0.4 & 0.4 & 0.2 & 0.1 \\
\hline Total C $\left(g \mathrm{~kg}^{-1}\right)$ & 36.3 & 8.1 & 5.0 & 5.1 & 3.4 \\
\hline $\mathrm{C} / \mathrm{N}$ ratio & 13.3 & 6.3 & 8.5 & 9.4 & 11.0 \\
\hline$P\left(g k^{-1}\right)$ & 0.37 & 0.20 & 0.15 & 0.74 & 0.39 \\
\hline$K\left(g k g^{-1}\right)$ & 1.37 & 1.25 & 1.19 & 1.14 & 0.96 \\
\hline $\operatorname{Mg}\left(g \mathrm{~kg}^{-1}\right)$ & 0.24 & 0.19 & 0.08 & 0.06 & 0.09 \\
\hline $\mathrm{Ca}\left(g \mathrm{~kg}^{-1}\right)$ & 1.77 & 1.23 & 0.06 & 0.07 & 0.03 \\
\hline $\mathrm{Na}\left(g \mathrm{~kg}^{-1}\right)$ & 0.52 & 0.51 & 2.09 & 1.27 & 1.70 \\
\hline$S\left(g k^{-1}\right)$ & 0.24 & 0.08 & 0.05 & 0.06 & 0.04 \\
\hline
\end{tabular}




\subsection{BMP assay}

336 The BMP assay was terminated after 40 days. The methane potential of native

337 substrate with addition of spent substrate was significantly different depending on

338 strain choice $(p=0.0009)$, with no effect of the dose of spent medium added or

339 interaction of strain and dose observed (Table 4). Native substrate with spent

340 medium had BMP levels of 342.0-380.5 $\mathrm{ml} \mathrm{CH}_{4} / \mathrm{g}$ VS (Table 5). Native substrate had

341 a BMP of $323.0 \pm 17.0 \mathrm{ml} \mathrm{CH}_{4} / \mathrm{g}$ VS. Cellulose controls yielded $392.3 \pm 31.0 \mathrm{ml} \mathrm{CH} 4 / \mathrm{g}$,

342 indicating that the inoculum performed adequately, and inoculum controls produced

$343 \quad 70.7 \pm 21.3 \mathrm{ml} \mathrm{CH}_{4}$. 
345 Table 4. ANOVA table for effects of strain choice and spent medium dosage on

346 downstream biomethanation potential

\begin{tabular}{lccccc}
\hline Factor & DF & Sum sq. & Mean sq. & F value & p-value \\
\hline AMPTS system & 2 & 7595.2 & 3797.6 & 10.1089 & 0.0005 \\
Strain & 2 & 6890.2 & 3445.1 & 9.1707 & 0.0009 \\
Dose & 1 & 14.3 & 14.3 & 0.0381 & 0.8467 \\
Strain:Dose & 2 & 2284.8 & 1142.4 & 3.0410 & 0.0644 \\
Residuals & 27 & 10143.0 & 375.7 & & \\
\end{tabular}

348 Table 5. Biomethanation potential (BMP) of native substrate with addition of spent

349 medium from the yeast cultivations according to the fitted linear model

\begin{tabular}{llc}
\hline Strain & BMP $(\mathbf{m l ~ C H} / \mathbf{g ~ V S})$ & SE \\
\hline W. anomalus & 350.7 & 13.0 \\
$P$. kudriavzevii & 342.0 & 17.5 \\
B. adeninivorans & 380.5 & 17.2
\end{tabular}




\section{Discussion}

352 In this study, we have produced yeast biomass from the liquid fraction of a substrate

353 from a Swedish co-digestion biogas plant. Depending on the yeast strain, biomass

354 concentrations reached 7.0-14.8 $\mathrm{g} / \mathrm{l}$ after $12-15 \mathrm{~h}$. By including the spent medium

355 from yeast fermentation in the AD slurry, we were also able to assess the relative

356 effects of each yeast strain on downstream methane potential.

358 For yeast-based SCP to be a viable co-product at a biogas plant, the organism must

359 be able to utilize the substrate used at the plant. The species evaluated here grew

360 well on the biogas substrate, with the highest final biomass productivity being $0.99 \mathrm{~g}$

$361 \mathrm{I}^{-1} \mathrm{~h}^{-1}$, with only minor efforts made to optimize cultivation conditions. Initial

362 experiments, carried out in shake flasks and in aerated 96-well deep-well plates,

363 were conducted to determine suitable fermentation parameters, but no subsequent

364 optimization was conducted. Furthermore, fermentations were performed at the same $365 \mathrm{pH}$ for all strains, in order to get representative spent substrates for the BMP assay. It

366 is worth noting that none of the yeast strains were able to grow at a $\mathrm{pH}$ of below 6 ,

367 likely due to the presence of weak acids in the substrate. The substrate otherwise

368 proved non-toxic to the yeast and no dilution was necessary. This is important for a

369 biogas plant, as further addition of water would lower the organic loading rate and

370 hydraulic retention time, compromising methane production.

372 Crude protein contents of the yeast biomass were lower than what has been reported

373 in the literature for fodder yeast, which range from 34.3-48.2 on a dry weight basis

374 (Tacon et al., 2009), whereas the levels in this study ranged from 22.6 to 32.7. 
375 However, much of the crude protein was accounted for by the amino acid analysis,

376 indicating low levels of non-protein nitrogen sources. Amino acid compositions of the

377 yeast biomass were similar to those found in the literature for other yeasts used as

378 fish feed (Tacon et al., 2009), with methionine being the most limiting amino acid.

379 Notably, lysine levels were close to the requirements of finfish. Lysine is commonly a

380 limiting amino acid, especially in feed ingredients of vegetable origin but also in many

381 species of yeast (Tacon et al., 2009). With further optimization, it is likely that the

382 protein content could be increased. Rajoka et al. (2006), in a study using Candida

383 utilis, found that true protein contents increased during the first 24 hours of

384 cultivation. Likewise, for Saccharomyces cerevisiae it was shown that protein

385 contents were highest after $36 \mathrm{~h}$, for two out of three strains evaluated (Novak,

386 2007). In the present study, however, cultivations were terminated after $12-15 \mathrm{~h}$,

387 suggesting an obvious route for optimization.

388

389 The choice of yeast strain proved to be important both for product yields as well as

390 for downstream BMP. The best-performing yeast strain, B. adeninivorans, produced

391 approximately twice the amount of biomass compared to the other two species, with

392 a similar protein content. Accordingly, final biomass productivity was also

393 approximately double compared to the two other strains. It is possible that this is due

394 in part to the higher cultivation temperature used for this strain. Rajoka et al. (2006)

395 found that temperature had a large impact on crude protein contents of yeast

396 biomass, which they attributed to increased transport of nutrients over the cell

397 membrane. Interestingly, $B$. adeninivorans also had the highest BMP when mixing its

398 spent substrate with native biogas substrate, suggesting a synergistic effect of this 
yeast treatment on the AD process and highlighting the importance of yeast strain choice for overall financial viability. It is worth mentioning that the production of yeast

401 biomass in all cases exceeded the reduction of TS in the substrate during cultivation.

402 This finding is an artifact of the way TS and VS are measured, which discounts all

403 compounds with a boiling point below $105^{\circ} \mathrm{C}$, such as several organic acids

404 abundantly present in household waste.

405

Although the results of this initial study are promising, future scale-up studies are needed need to address a number of limitations, some of which are summarized below. First, cultivations should be performed on minimally filtered substrate. In this

409 study, sterile-filtered substrate was used in order to facilitate analyses, such as

410 biomass dry matter concentration and CFU counts. Despite the substrate being

411 hygienized $\left(70^{\circ} \mathrm{C}\right.$ for at least one hour), it cannot be regarded as sterile and it

412 remains to be seen whether this proves a challenge in scaling up. Second, efficient

413 product recovery will be essential for the financial outcome of the process, but was

414 not investigated in the present study. Third, the downstream effects on methane

415 production should be more rigorously characterized. Whereas the present study used

416 batch tests for assessing methane potential, a more thorough study would use a

417 continuous biogas reactor with continuous feeding of spent substrate. Further,

418 although the results suggest an increase in methane potential over the native

419 substrate, it is fair to assume that sterile filtration of the substrate acts as a

420 pretreatment by removing the more recalcitrant particulate matter. Thus, future

421 studies, using the setup described above and including the retentate in the biogas

422 reactor, could better assess the effects of yeast cultivations on the economics of the 
423 integrated process, preferably by examining effects on different types of biogas

424 substrates using several inocula.

425

426

\section{Conclusions}

427 Biogas plants are in several ways well suited for production of products other than

428 methane and digestate. In this initial investigative study, we demonstrate that co-

429 production of yeast SCP on biogas co-digestion substrate is feasible, with high

430 growth rates attained during the batch cultivations. Furthermore, yeast biomass

431 amino acid profiles were similar to yeast SCP already in use in the aquaculture

432 industry. Due to the presence of logistics networks and year-round substrate

433 availability, co-production of yeast SCP and biogas may be an attractive option for

434 diversifying biogas plant outputs. Further optimization of cultivation parameters is

435 likely to improve product yield and productivity; however, scale-up experiments are

436 required to assess the financial and technological viability of this integrated process.

\section{Acknowledgements}

439 The authors wish to thank Simon Isaksson and Albina Bakeeva for help with setting 440 up the BMP assay.

\section{Funding}

443 Financial support for this study was provided by Karlskoga Energi \& Miljö and the NJ

444 faculty at the Swedish University of Agricultural Sciences. The funding bodies did not

445 have any role in the study design, collection and interpretation of data, writing of this

446 manuscript, and choice to submit it for publication. 


\section{References}

Angelidaki, I., Alves, M., Bolzonella, D., Borzacconi, L., Campos, J.L., Guwy, A.J., Kalyuzhnyi, S., Jenicek, P., van Lier, J.B., 2009. Defining the biomethane potential (BMP) of solid organic wastes and energy crops: a proposed protocol for batch assays. Water Sci Technol 59, 927934.

Badshah, M., Lam, D.M., Liu, J., Mattiasson, B., 2012. Use of an Automatic Methane Potential Test System for evaluating the biomethane potential of sugarcane bagasse after different treatments. Bioresource Technology 114, 262-269. Williams, M., 2015. Feeding 9 billion by 2050 - Putting fish back on the menu. Food Security 7, 261-274.

Cao, L., Wang, W., Yang, C., Yang, Y., Diana, J., Yakupitiyage, A., Luo, Z., Li, D., 2007. Application of microbial phytase in fish feed. Enzyme and Microbial Technology 40, 497-507. Carlsson, M., Lagerkvist, A., Morgan-Sagastume, F., 2012. The effects of substrate pretreatment on anaerobic digestion systems: A review. Waste Management 32, 1634-1650. Delgado, J.G., Reyes, J.M.M., 2018. Potential of microbial-derived nutrients for aquaculture development. Reviews in Aquaculture 10, 224-246. FAO, 2018. The State of World Fisheries and Aquaculture 2018. FAO. Francis, G., Makkar, H.P.S., Becker, K., 2001. Antinutritional factors present in plant-derived alternate fish feed ingredients and their effects in fish. Aquaculture 199, 197-227. Goldberg, I., 1985. Single Cell Protein. Springer Berlin Heidelberg, Berlin, Heidelberg. Hartmann, H., Ahring, B.K., 2006. Strategies for the anaerobic digestion of the organic fraction of municipal solid waste: an overview. Water Sci Technol 53, 7-22. Hellström, A., Qvirist, L., Svanberg, U., Vilg, J.V., Andlid, T., 2015. Secretion of non-cell-bound phytase by the yeast Pichia kudriavzevii TY13. Journal of Applied Microbiology 118, 11261136. Holm-Nielsen, J.B., Al Seadi, T., Oleskowicz-Popiel, P., 2009. The future of anaerobic digestion and biogas utilization. Bioresource Technology 100, 5478-5484. Huyben, D., Nyman, A., Vidaković, A., Passoth, V., Moccia, R., Kiessling, A., Dicksved, J., Lundh, T., 2017. Effects of dietary inclusion of the yeasts Saccharomyces cerevisiae and Wickerhamomyces anomalus on gut microbiota of rainbow trout. Aquaculture 473, 528-537. Kleerebezem, R., Joosse, B., Rozendal, R., Van Loosdrecht, M.C.M., 2015. Anaerobic digestion without biogas? Reviews in Environmental Science and Bio/Technology 14, 787 -

482 Middelhoven, W.J., de Jong, I.M., de Winter, M., 1991. Arxula adeninivorans, a yeast assimilating many nitrogenous and aromatic compounds. Antonie van Leeuwenhoek 59, 129-137. opportunities for agricultural digestate valorization: current situation and perspectives. Energy \& Environmental Science 8, 2600-2621. Nordic Committee on Food Analysis, 2003. NMKL 6. Nitrogen. Determination in foods and feeds according to Kjeldahl, 4 ed. NMKL, Oslo. 
Olstorpe, M., Schnürer, J., Passoth, V., 2009. Screening of yeast strains for phytase activity.

494 FEMS yeast research 9, 478-488.

495 Passoth, V., Fredlund, E., Druvefors, U.A., Schnürer, J., 2006. Biotechnology, physiology and genetics of the yeast Pichia anomala. FEMS yeast research 6, 3-13.

497 Passoth, V., Olstorpe, M., Schnürer, J., 2010. Past, present and future research directions

498 with Pichia anomala. Antonie van Leeuwenhoek 99, 121-125.

499 Peters, L., Uhlenhut, F., Biernacki, P., Steinigeweg, S., 2018. Status of Demand-Driven Biogas

500 Concepts to Cover Residual Load Rises. ChemBioEng Reviews 5, 163-172.

501 R Core Team, 2019. R: A language and environment for statistical computing. R Foundation 502 for Statistical Computing, Vienna, Austria.

503 Radecka, D., Mukherjee, V., Mateo, R.Q., Stojiljkovic, M., Foulquié-Moreno, M.R., Thevelein, 504 J.M., 2015. Looking beyond Saccharomyces: the potential of non-conventional yeast species 505 for desirable traits in bioethanol fermentation. FEMS yeast research 15, fov053.

506 Rajoka, M.I., Khan, S.H., Jabbar, M.A., Awan, M.S., Hashmi, A.S., 2006. Kinetics of batch 507 single cell protein production from rice polishings with Candida utilis in continuously aerated 508 tank reactors. Bioresource Technology 97, 1934-1941.

509 Rumsey, G.L., Winfree, R.A., Hughes, S.G., 1992. Nutritional value of dietary nucleic acids and 510 purine bases to rainbow trout (Oncorhynchus mykiss). Aquaculture 108, 97-110.

511 Sano, K., Fukuhara, H., Nakamura, Y., 1999. Phytase of the yeast Arxula adeninivorans.

512 Biotechnology Letters 21, 33-38.

513 Scarlat, N., Dallemand, J.-F., Fahl, F., 2018. Biogas: Developments and perspectives in 514 Europe. Renewable Energy 129, 457-472.

515 Schnürer, J., Jonsson, A., 2010. Pichia anomala J121: a 30-year overnight near success

516 biopreservation story. Antonie van Leeuwenhoek 99, 5-12.

517 Tacon, A.G.J., Metian, M., 2009. Fishing for feed or fishing for food: increasing global

518 competition for small pelagic forage fish. Ambio 38, 294-302.

519 Tacon, A.G.J., Metian, M., Hasan, M.R., 2009. Feed Ingredients and Fertilizers for Farmed 520 Aquatic Animals. FAO, Rome.

521 The Commission of the European Communities, 1998. Community methods of analysis for 522 the determination of amino-acids, crude oils and fats, and olaquindox in feedingstuffs and 523 amending Directive 71/393/EEC. Official Journal of the European Communities 257, 14-28. 524 Wickham, H., 2009. ggplot2: Elegant Graphics for Data Analysis. Springer-Verlag, New York. 